UDK: 821.134.2(892).09-32 Рикелме J.

821.163.41.09-32 Нушић Б.

DOI: https://doi.org/10.18485/legado_hispanico.2020.ch8

\author{
Luiza Valožić ${ }^{1}$ \\ Universidad de Belgrado \\ Serbia
}

\title{
ANÁLISIS INTERTEXTUAL COMO PUNTO DE ENCUENTRO: BRANISLAV NUŠIĆ Y YULA RIQUELME
}

\begin{abstract}
Resumen
El concepto de intertextualidad ha tenido un gran eco en el análisis de obras literarias desde su acuñación en la segunda mitad del siglo XX. Consideramos que este concepto puede ofrecer hoy un marco teórico válido siempre y cuando se delimite y no pretenda sustituir a ningún análisis literario o a la crítica literaria. Sobre todo consideramos su utilidad en cuanto a su potencial de mostrar relaciones entre obras literarias aparentemente lejanas.

Presentamos en este artículo un análisis intertextual de dos obras literarias. Concretamente, de un relato corto de la escritora paraguaya Yula Riquelme, publicado en los años 90 del siglo XX y de una comedia para el teatro del escritor serbio Branislav Nušić, escrita en el primer tercio del siglo XX. El planteamiento teórico de la intertextualidad contempla tanto la ausencia como la presencia de la referencialidad en los análisis de obras literarias y otros. Dado que no existen evidencias de referencialidad entre estas dos obras, la intertextualidad se presenta como el marco teórico más apropiado para delinear las relaciones que hemos encontrado entre ellas.

Las dos obras tratan el tema del fallecimiento y de la situación posterior del trato entre los herederos y la apertura del testamento. Veremos diferentes

\footnotetext{
${ }^{1}$ luiza.valozic@gmail.com
} 
relaciones que existen entre dichas obras con referencia a varios aspectos como el tema, el título, los personajes, su carácter y actitud, elementos estructurales de las obras y elementos temáticos vinculados con el fallecimiento y los correspondientes procedimientos legales y tradiciones. Nuestro análisis nos permitirá ver puntos de encuentro existentes entre dos obras alejadas geográfica, lingüística, cultural y temporalmente, pero cercanas si las observamos desde la perspectiva de la intertextualidad.

Palabras clave: intertextualidad, relaciones textuales, Yula Riquelme, Branislav Nušić.

\section{Introducción}

El tema que nos ocupa aquí es un análisis de las relaciones observadas entre dos obras literarias, la comedia del escritor serbio Branislav Nušić, Ožalošćena porodica (La familia afligida) ${ }^{2}$ y el relato Herederos a la suerte de la escritora paraguaya Yula Riquelme de Molina. Para ello nos servimos del marco teórico de la intertextualidad.

Partimos de la asunción de que las dos obras literarias que analizamos carecen de referencialidad. El relato de Yula Riquelme es posterior a la obra de teatro de Nušić. La primera fue publicada en 1995, mientras que la segunda fue representada por primera vez en 1935, y fue escrita después de 1929. La obra de Nušić La familia afligida no cuenta con una traducción al español, y en el análisis crítico de la obra de Yula Riquelme no hemos encontrado ningún indicio de que la autora conozca la obra de Nušić. De aquí asumimos que no existe ningún tipo de referencialidad entre las dos obras, y por ello elegimos el marco teórico que nos ofrece la intertextualidad, ya que la intertextualidad admite tanto la ausencia como la presencia de la referencialidad en los análisis de obras literarias y otros.

Ahora bien, no descartamos la posibilidad de que exista algún tipo de correlación de cada una de las obras que analizamos con alguna

\footnotetext{
${ }^{2}$ El título original de la obra teatral de Branislav Nušić en serbio es Ožalošćena porodica. Según los datos que nos constan, esta obra de Nušić no cuenta con una traducción al español. Por este motivo, y para los propósitos de este artículo, la traducción tanto del título de la obra como de todos sus segmentos que se utilizan para ilustrar las relaciones observadas son realizados por la autora de este artículo. En las notas a pie de página se aporta la versión original de los segmentos de texto utilizados en su versión original en serbio. Por motivos de coherencia textual presentamos los fragmentos en alfabeto latino, aunque la edición original de la obra es en cirílico.
} 
otra anterior que a su vez las pondría en contacto entre sí. Por ejemplo, como veremos más adelante, Gligorić sostiene que en La familia afligida Nušić toma de Balzac el motivo del egoísmo ciego y de la avaricia. No hemos encontrado un análisis similar con respecto a la obra de Yula Riquelme, sin embargo, insistimos en la idea de que no desestimamos la probabilidad de la existencia de una o varias obras anteriores que tengan una relación dialógica, en términos bajtinianos, con ambas o alguna de las obras analizadas.

Por lo tanto, dado el hecho de que hemos escogido para nuestro análisis dos obras literarias sin una relación de referencialidad, acudimos al marco teórico que nos ofrece la intertextualidad y realizamos un análisis de dos obras literarias con relaciones implícitas. Más adelante también comentaremos que nuestra elección del marco teórico y metodológico de la intertextualidad de ningún modo asume la lectura de este concepto como abandono o negación de la crítica literaria en sus dimensiones tanto históricas como teóricas y metodológicas. Percibimos la intertextualidad como una opción teórica para el análisis que deseamos llevar a cabo.

La intertextualidad nos permite ver las relaciones entre estos dos textos literarios aparentemente lejanos desde diferentes puntos de vista como son el geográfico, lingüístico, cultural y temporal, esto es, un relato del siglo XX de una autora paraguaya y una obra teatral del siglo XIX de un autor serbio. Una lectura intertextual de estas dos obras nos abre una nueva puerta para la percepción de una cercanía, una interconexión entre ellas, y aquí precisamente reside el beneficio que nos aporta tanto en el sentido personal (de lector) como lingüístico, estético y cultural.

Cabe destacar que desde el punto de vista de los estudios literarios, la crítica literaria y la traducción contamos con un lazo histórico que une a Serbia (y otros países de los Balcanes como Croacia, Bosnia, Eslovenia, etc.), España e Hispanoamérica. Un ejemplo del estudio de la literatura serbia y eslava en España es el trabajo de Presa de 1997. También encontramos un rico y amplio análisis de la presencia de las literaturas hispánicas en Serbia en el trabajo de Soldatić (2010).

\section{Marco teórico}

La perspectiva teórica que adoptamos en este análisis se asienta sobre los postulados de Kristeva y Barthes sobre la intertextualidad. En el Diccionario de términos clave de ELE encontramos la siguiente definición del concepto de intertextualidad: 
La intertextualidad es la relación que un texto (oral o escrito) mantiene con otros textos (orales o escritos), ya sean contemporáneos o históricos; el conjunto de textos con los que se vincula explícita o implícitamente un texto constituye un tipo especial de contexto, que influye tanto en la producción como en la comprensión del discurso.

Seguimos la definición de intertextualidad que Kristeva acuñó en su de sobra conocido artículo de 1969 en el que habla sobre Bajtín: «[...] todo texto se construye como mosaico de citas, todo texto es absorción y transformación de otro texto. En lugar de la noción de intersubjetividad se instala la de intertextualidad, y el lenguaje poético se lee, al menos, como doble» (Kristeva 1981: 190).

En sintonía con esta visión de intertextualidad está también la lectura de dicho concepto por parte de Barthes (1994: 78):

La intertextualidad en la que está inserto todo texto, ya que él mismo es el entretexto de otro texto, no debe confundirse con ningún origen del texto buscar las «fuentes», las «influencias» de una obra es satisfacer el mito de la filiación; las citas que forman un texto son anónimas, ilocalizables y, no obstante, ya leídas antes: son citas sin entrecomillado.

Como hemos dicho al principio, no nos situamos en una interpretación de la intertextualidad como único marco teórico posible para el análisis literario, y menos aún para la crítica literaria, sino como un marco teórico posible para ciertos análisis. Lešić efectúa un amplio y detallado análisis de los conceptos clave de la obra de Bajtín y de algunas lecturas que Kristeva hace de ellos. En este sentido, estamos de acuerdo con Lešić cuando habla de que la intertextualidad de Kristeva no es sinónimo de los conceptos de «dialoguismo», «heteroglosia» y "polifonía» de Bajtín (Lešić 2011: 194-211). Es preciso delimitar la intertextualidad con el objetivo de poder operar con ella en el ámbito teórico, y Lešić realiza una matización que nos parece apropiada (2011: 235-236):

La intertextualidad puede ser un concepto útil siempre y cuando no pretenda darnos todas las respuestas a todas las preguntas sobre cómo un texto literario crea el sentido, o sobre cómo nosotros encontramos significados en él [...] Sin embrago, si somos conscientes de estas limitaciones, creo que este concepto es de gran utilidad, sea como un concepto general que describe cualquier relación entre textos, o como el tipo, definido en términos barthesianos, de «relaciones entre el texto y diferentes lenguas o prácticas de significación de una cultura y de 
su relación con aquellos textos que articulan las posibilidades de esa cultura». ${ }^{3}$

Por lo tanto, teniendo en cuenta lo anteriormente dicho, definimos el análisis presentado aquí como un análisis intertextual de las relaciones observadas entre dos obras literarias que no tienen unarelación referencial. Las dos obras escogidas constituyen el conjunto de textos que se vinculan implícitamente y de esta forma constituyen el contexto especial del que se habla en la definición de Kristeva, y además, no buscamos «fuentes» o «influencias» como menciona Barthes en su definición.

\section{Branislav Nušić y su obra}

Branislav Nušić nació en Belgrado el 8 de octubre de 1864. Gligorić ilustra su prolífica creación de comedias delineando la relación temporal entre la primera comedia que escribió para el teatro con veinte años, Narodni poslanik (El diputado) ${ }^{4}$, y su comedia Pokojnik (El difunto), que escribió cuando tenía alrededor de setenta años. En palabras de Gligorić, Nušić vivía para el teatro y veía la vida como un teatro. Además de poseer mucha vitalidad, una gran capacidad de observación y un humor vivaz, también tenía naturaleza, instintos, temperamento e imaginación de un actor teatral. Murió el 19 de enero de 1938 (Gligorić 1964: 7-16).

Gracias al esfuerzo de las personas participantes en el proyecto ¡Bienvenido, señor Nušić!, de la Asociación teatral El valor y la risa de Madrid y de la Asociación yugoslava del Teatro y del Arte Mediterráneos de Belgrado, en el año 2013 se publicó la primera traducción de una obra de Branislav Nušić al español. Se trata de su obra teatral Sumnjivo Lice (El sospechoso), traducida por Nataša Guzina. En la Introducción ${ }^{5}$ a esta traducción, Stojanović presenta a Branislav Nušić como dramaturgo, narrador, novelista y cuentista, y perfila los detalles más destacados de la vida del autor (Nušić 2013: 3-4):

\footnotetext{
3 Traducción del serbio al español realizada por la autora de este artículo. El entrecomillado aparece en el original, ya que Lešić indica en una nota a pie de página que se refiere al siguiente trabajo: Johnatan Culler. The Pursuit of Signs: Semiotics, Literature, Deconstruction. London: Routledge and Kegan Paul, 1981.

${ }^{4}$ Tomamos las traducciones al español de las obras Narodni poslanik (El diputado) y Pokojnik (El difunto) de la Introducción a la traducción al español de la pieza teatral de Nušić Sumnjivo lice (El sospechoso) (Nušić 2013: 5).

${ }^{5}$ La Introducción a la traducción de la pieza teatral de Nušić Sumnjivo lice (El sospechoso) es escrita por la profesora Jasna Stojanović de la Facultad de Filología de la Universidad de Belgrado (Nušić 2013: 3-5).
} 
Durante su turbulenta vida ejerció varios cargos en teatros de Belgrado, Novi Sad, Sarajevo y Skopje (director, director de escena, fundador), siendo en otras etapas de su existencia soldado, prisionero político, diplomático, funcionario de varios ministerios y miembro de la Academia serbia de Ciencias y Artes. Sus mejores obras retratan en clave cómica la mentalidad balcánica y el ambiente socio-cultural de la Serbia de entonces. Acapararon en seguida la atención del público y convirtieron a Nušić en el autor con mayor presencia en los escenarios serbios y yugoslavos durante muchos decenios. Sin embargo, no fue así con la crítica, que despreció su humor, calificándolo de «bajo» e ignoró su caricatura de los funcionarios públicos y de todos los que ejercen algún tipo de poder -metas predilectas de la risa del comediógrafo.

La obra La familia afligida de Nušić es una comedia para el teatro, escrita después de 1929 (Gligorić 1964: 14), y estrenada en Sofía en el año $1935^{6}$.

De acuerdo con el análisis de Gligorić, la comedia La familia afligida Nušić es una comedia de carácter en la que el autor toma de Balzac el motivo del egoísmo ciego y de la avaricia que no se detiene ni siguiera ante la muerte. En cuanto el difunto es enterrado, diversos familiares, cuyos vínculos con el difunto no son bien claros, aparecen en su casa y desean repartirse la herencia. Esta actitud es motivo para el uso del humor negro y de la tragicomedia. El personaje principal es Agaton, presidente de diputación provincial jubilado, un hombre robusto, astuto, prepotente. Su objetivo es burlar al resto de los familiares y conseguir la mayor parte de la herencia. Nušić pone mucho humor en ilustrar su actitud y sus peripecias, pero no lo presenta como un personaje negativo (1964: 48-49). En esta última idea coincide Đoković y sostiene que Nušić no critica a Agaton, ya que él representa el estamento social de aquellos que solo se adaptan a las circunstancias, no de aquellos que realmente tienen el poder (Đoković 1964: 335).

La hija extramatrimonial del difunto, Danica, es otro personaje clave. La familia se queda estupefacta ante el hecho de que Danica es la heredera de la fortuna del difunto. Nušić la dota de todas las virtudes, y ella queda como vencedora absoluta cuando la familia oportunista admite la derrota y se retira. En cuanto a la composición, Gligorić sostiene que la obra está muy bien compuesta y que contiene personajes con aires de provincianos, muy vivos y creados con una gran dosis de humor. Asimismo la acción tiene mucho nervio y espíritu que no decae hasta el final (1964: 49-51).

\footnotetext{
${ }^{6}$ Dato del estreno de La familia afligida que consta en la página oficial del Teatro nacional de Serbia: [https://www.narodnopozoriste.rs/ozaloscena-porodica-1].
} 
Para Đoković (1964: 157), la comedia La familia afligida recoge uno de los grandes temas que aborda Nušić, la gente insignificante con grandes apetitos. En su opinión, el espectador empieza a comprender la trama primero de forma visual cuando aparecen en escena los familiares vestidos de luto y comienzan a suspirar y lamentar lo pronto que se ha marchado un hombre tan bueno, honrado y caritativo. Enseguida comenzarán a lanzarse pullas y a mostrar su hipocresía. El espectador puede apreciar rápidamente que tendrá ante sí una comedia de egoísmos confrontados en un ambiente que Đoković tilda de «tristeza decorativa» (Đoković 1964: 185).

En esta comedia no hay incertidumbres. La idea es clara, reírse de la codicia de los herederos. Đoković también habla del dominio de Agaton, incluso al final de la obra cuando dice que el abogado, albacea del testamento, es su hijo extramatrimonial. Agaton se queda aturdido ante el efecto que su mentira provoca y cierra la obra afirmando que ahora sí ha «arreglado la cosa» (Đoković 1964: 188-189).

Cabe mencionar también a la persona que cuidaba de Mata Todorović, la tía, que junto con su sobrina Danica vive en una casa adjunta a la casa principal. El nombre de la tía no se menciona. La familia se muestra recelosa tanto de la tía como de Danica a lo largo de toda la obra.

La parte central de la obra se inicia cuando, desconfiando de la tía, de Danica y del abogado, los familiares deciden mudarse a la casa del difunto para cuidarla y evitar que nadie se lleve nada de valor. Incluso en esta maniobra supuestamente bienintencionada intentan engañarse mutuamente y mudarse a la casa sin que lo sepan los demás.

En diferentes escenas vemos que tanto la tía como Danica y el abogado no tienen ninguna intención siniestra, a diferencia del resto de los familiares.

\section{Yula Riquelme de Molinas y su obra}

Yula Riquelme de Molinas nació en Asunción, Paraguay, en el año 1942. Durante muchos años fue miembro activo del Taller de Cuento Breve dirigido por Hugo Rodríguez Alcalá. Aparte de ser escritora de cuentos también publicó en 1976 el poemario Los moradores del vórtice, y la novela fantástica Puerta en $1994^{7}$.

Es considerada una de las mejores escritoras del Paraguay, y destaca, además, por ser una de las escritoras más premiadas del país, aunque ha sido premiada también en otros países, como Argentina o Uruguay. El

\footnotetext{
${ }^{7}$ La fuente de los datos biográficos es el sitio web oficial de la Sociedad de Escritores del Paraguay: [http://www.sep.org.py/autores.php?id_miembro=38].
} 
estilo personal de Yula Riquelme es calificado por Peiró como bastante bien definido. Sus relatos son continuos, sin punto y aparte y predominan en ellos las frases breves. De esta forma se construye el discurso como una totalidad en la que no existe una interrupción entre los pensamientos y las palabras del personaje que narra (Peiró 2002: 849-850).

El relato breve Herederos a la suerte, que forma parte de nuestro análisis intertextual, está incluido en el libro de cuentos titulado Bazar de cuentos, publicado en el año 1995. Se compone de veinte relatos que reflejan el estilo propio de la autora. Perió destaca los dos temas centrales de esta obra, esto es, lo fantástico y lo feminista. La autora examina la situación actual de la mujer en Paraguay y denuncia su discriminación social, al igual que la hipocresía social. Coincidimos con Peiró en situar el cuento Herederos a la suerte en esta segunda categoría. Más concretamente, en el cuento se hace crítica de la hipocresía social después de un fallecimiento (Peiró 2002: 859-860).

En Herederos a la suerte, siete hijos del fallecido don Agustín esperan que se abra el testamento y se reparta su gran fortuna procurando en todo momento guardar las formas. El primogénito, Norberto trata con el abogado, doctor Paredes, todos los detalles legales pertinentes. Paula es la mujer que cuidó de don Agustín hasta su muerte y a lo largo del cuento su presencia despierta desasosiego en los hijos. Este sentimiento se intensifica cuando descubren a través del abogado que ella ha de estar presente en la apertura del testamento. Al final, Paula resulta ser la inesperada única heredera de la fortuna de don Agustín que se casó con ella sin el conocimiento de sus hijos.

\section{Análisis intertextual}

Con el fin de hacer más amenas las referencias a las obras utilizadas en el análisis, se aplican las siguientes abreviaciones, $H S$ para el relato Herederos a la suerte y FA para la obra teatral La familia afligida.

Como hemos podido ver en los apartados anteriores es común a ambas obras el tema de crítica de la hipocresía lo que constituye la primera relación entre ellas. La segunda relación la encontramos en los títulos, Herederos a la suerte y La familia afligida donde se percibe un sentido irónico, ya que el contenido de las obras nos revela que ni los herederos consiguen su suerte ni la familia está afligida. Esto lo veremos también a lo largo del análisis de los fragmentos escogidos.

Las otras relaciones observadas se refieren a diferentes elementos de las obras, a saber, los personajes, su carácter y actitud, elementos 
estructurales de las obras y elementos temáticos relacionados con el fallecimiento y los correspondientes procedimientos legales y tradiciones. En la exposición de las otras relaciones observadas seguimos la evolución de la acción en ambas obras.

En tercer lugar, encontramos una relación en cuanto a que es el mismo personaje el que abre y cierra la obra. Concretamente se trata del personaje principal, que en el relato de $H S$ es Paula y en la obra $F A$ es Agaton.

En el relato $H S$ el nombre de Paula es la primera y la última palabra del relato. Al inicio del relato ella sale de la habitación donde está el difunto Don Agustín: «Paula cerró el maletín y salió de la alcoba lujosa» (Riquelme 2000: 56). Y al final, dentro del texto del testamento, en palabras de Don Agustín, está la frase que cierra el relato: «Me he casado con Paula» (Riquelme 2000: 59).

La obra de B. Nušić comienza con la intervención de Agaton: «iQué hombre, dios mío! Como si nunca hubiera existido» ${ }^{8}$ y también termina con sus palabras: «ßBueno, ahora sí que he arreglado la cosa!...»" Agaton pronuncia estas palabras al final cuando se da cuenta de cuánto ha complicado la situación con su última ocurrencia, esto es, decir que el abogado, doctor Petrović, es su hijo extramatrimonial en un intento, quizás desesperado, de seguir en la pugna por obtener un trozo de la herencia.

La cuarta relación está reflejada en la figura que hace de representante de la familia, sobre todo en la interacción con el abogado. En el relato $H S$ se trata de Norberto, «el primogénito», y en el caso de la obra teatral $F A$ esta tarea la asume Agaton por iniciativa propia. Tanto Norberto como Agaton tratan con los abogados el tema de la apertura del testamento.

En la figura del abogado encontramos la quinta relación. De su actitud e interacción sobre todo con los representantes de las familias se infiere que tanto doctor Paredes en $H S$ como doctor Petrović en FA son hombres razonables, honestos y fieles a los deseos e intereses del difunto.

La sexta relación está presente en el momento de apertura del testamento. Los abogados aconsejan que esta no sea inmediata y al principio recomiendan un período de espera que coincide en ambos casos con el tiempo dedicado al luto por el difunto marcado por la tradición

\footnotetext{
${ }^{8}$ Texto original en serbio: „Što ti je čovek, bože moj! Kao da ga nije ni bilo“ (Nušić 2005: 287).

${ }^{9}$ Texto original en serbio: „E, sad sam udesio stvar!“ (Nušić 2005: 365).
} 
religiosa imperante en cada cultura, nueve días correspondientes al novenario en $H S$, y cuarenta días en $F A$. Pero, como veremos, este plan inicial se tuerce y en las dos obras el procedimiento de abrir el testamento se realiza con mayor prontitud, aunque por motivos diferentes.

El siguiente fragmento ilustra la recomendación inicial del abogado en $H S$ : «La noche los sorprendió sin haber hablado de la apertura del testamento. Claro que el abogado dijo que para eso no había prisa, que era mejor abrirlo en calma... Quizá después de las misas novenarias...» (Riquelme 2000: 57).

En $H S$, en contra de las recomendaciones del abogado, la apertura del testamento se da la misma mañana del funeral de don Agustín. Hemos aludido antes a que el motivo del adelanto difiere en las dos obras. En el relato $H S$ esta diferencia se refleja en el procedimiento que tienen los hijos de don Agustín para tomar decisiones en común. El procedimiento consiste en echar las cosas a la suerte. Así, al igual que para todo lo demás, también echan a la suerte el día que el testamento debe ser abierto y la suerte: «[...] señaló el acto para esa misma mañana» (Riquleme 2000: 59).

Una parte del primer diálogo entre Danica y el abogado doctor Petrović en la obra teatral $F A$ ilustra, en primer lugar, la relación presente en la recomendación inicial del abogado y el cambio que se da respecto a esta al anticiparse la apertura del testamento, y en segundo lugar, la diferencia entre las dos obras. Lo que motiva al abogado en $F A$ para adelantar la apertura es el hecho de que la familia se ha mudado a la casa del difunto y es preciso echarla, aunque de un modo sutil que no cause escándalo. El abogado hace referencia a la segunda manera de poder conseguir esto, ya que la primera, llamar a la policía para que los eche a todos, la descarta por excesivamente brusca. Lo vemos en el siguiente fragmento:

ABOGADO: La otra manera sería solicitar al juzgado que el testamento se abriera enseguida.

DANICA: Yo he oído que hay que esperar cuarenta días para la apertura.

ABOGADO: Sí, ese solo era el deseo del difunto, pero no tiene base legal y no es obligatorio cumplirlo.

DANICA: ¿Pero, no sería mejor cumplir el deseo del difunto?

ABOGADO: Yo tampoco quiero ser irrespetuoso hacia su deseo, pero él solo previó esa posibilidad. A la nota donde declaró el deseo que se abra el testamento a los cuarenta días, añadió estas pocas palabras: «a no ser que el albacea considere necesario obrar de otro modo». Yo, por lo tanto, podría considerar que esta situación dicta dicha necesidad y mañana mismo se podría abrir el testamento. 
DANICA: ¿Y qué conseguiría con eso?

ABOGADO: Se sabría quién es el heredero y entonces los demás de desperdigarían. ${ }^{10}$

Como hemos visto, los personajes femeninos de Paula y Danica tienen mucha importancia en las respectivas obras, y en estas dos mujeres encontramos la séptima relación que se materializa a través de distintos elementos en los que también existen algunas diferencias.

Tanto Paula como Danica son las inesperadas herederas. Inesperadas desde el punto de vista de los familiares, porque en ambas obras los herederos esperan recibir su parte de la fortuna.

En $H S$ Paula es heredera y cuidadora de don Agustín. Su faceta de cuidadora la vemos en el siguiente fragmento: «Había hecho por el anciano lo que ningún miembro de la familia hiciera... Paula estudió algo de medicina. Esto, y su paciencia a toda prueba, la capacitaban para el manejo de viejos fastidiosos. Por eso y también por cómodos, los parientes dejaron a don Agustín enteramente a su cuidado» (Riquelme 2005: 58).

La diferencia entre las dos obras está en el personaje femenino que se ocupaba del cuidado del difunto porque en $F A$ hay otra mujer, la tía de Danica, que cumple el rol de la principal cuidadora de Mata Todorović y que también lo acompaña en los últimos momentos de su vida. A continuación está el fragmento en el que se menciona este papel de la tía en palabras de Agaton: «No, sino que estaba aquí en la casa, cuidó del difunto, fue en sus brazos donde murió, y... así, estaba aquí echando una mano» ${ }^{11}$.

Las referencias a la belleza y la bondad de Paula y de Danica están presentes en ambas obras. Concretamente, en $H S$, leemos en relación con

\footnotetext{
${ }^{10}$ Texto original en serbio:

ADVOKAT: Drugi način bio bi kada bih zahtevao od suda da se odmah otvori testament. DANICA: Ja sam čula da se mora čekati četrdeset dana do otvaranja.

ADVOKAT: Da, to je bila samo pokojnikova želja, ali ona nema osnova u zakonu i ne mora se ispuniti.

DANICA: Pa zar en bi ipak bilo bolje ispuniti želju pokojnikovu?

ADVOKAT: Ni ja ne želim da je vređam, ali je on sam predvideo ovakvu mogućnost. U zapisniku na kome je izjavio želju da se testament otvori posle četrdeset dana, dodao je i ovo nekoliko reči: „sem ako staralac nađe za neophodno da drugače postupi". Ja bih, dakle, mogao naći da ovakva situacija nalaže neophodnost i sutra bi već mogao biti otvroren testament.»

DANICA: A šta biste time učinili?

ABOGADO: Saznalo bi se ko je naslednik i tada bi se svi ostali razbegli (Nušić 2005: 324).

${ }^{11}$ Texto original en serbio: „Nije, nego, bila tu u kući, negovala pokojnika, na njenim je rukama i izdanuo, pa... tako, našla se tu" (Nušić 2005: 296).
} 
Paula: «Saltaba a la vista su belleza y no parecía mala persona» (Riquelme 2000: 58).

En cuanto a Danica, las primeras referencias a su belleza las hace Mića, uno de los familiares: «[...] Quién lo diría, en una casa llena de tristeza y aflicción, ¡una visión tan clara y cautivadora! [...] Cierto, una muchacha linda, hay que reconocerlo» ${ }^{12}$. A lo largo de la obra, otros personajes también hacen referencias a su belleza y a su juventud. A diferencia de $H S$, no se menciona explícitamente nada sobre la bondad de Danica. Esta característica de ella se deduce de diferentes interacciones con el resto de los personajes, sobre todo con el abogado. En la sexta escena del primer acto Danica habla con el abogado y se queja de que Mića le sugiere que después de que se abra el testamento y se establezca que él es uno de los herederos, ella podría quedarse a vivir en la casa hasta que él se case. Danica se siente ofendida por esta proposición indecente de Mića. Aunque el abogado después de escuchar lo que le cuenta Danica le dice que quizás las intenciones de Mića eran buenas, Danica no cambia de parecer, y así se lo dice al abogado:

ABOGADO: ¿Quizá él tiene buenas intenciones?

DANICA: ¿Y qué si tuviera buenas intenciones?

ABOGADO: Bueno, ¿y si él fuera el heredero?

DANICA (ofendida): ¿Usted realmente no ha podido formarse una opinión mejor sobre mí?

ABOGADO: Por dios, no se ofenda por eso, pero ya sabe cómo son las cosas, la riqueza a pesar de todo ha de tentar al hombre.

DANICA: ¿Ah, sí? O sea, ¿usted tampoco se siente fuerte ante la riqueza? ${ }^{13}$

Pero la figura de las dos mujeres y, sobre todo, su presencia de algún modo ligada al momento de la apertura del testamento es molesta para los familiares. Son vistas como un elemento ajeno que les incomoda.

\footnotetext{
${ }^{12}$ Texto original en serbio: „[...] MIĆA: Ko bi to rekao, u kući punoj tuge i žalosti, jedan tako vedar i očaravajući pogled. [...] Odista, lepuškasta devojčica, to se mora priznati“ (Nušić 2005: 292-293).

${ }_{13}^{13}$ Texto original en serbio:

ADVOKAT: Možda on ima kakve ozbiljne namere?

DANICA: Pa šta ako bi imao ozbiljne namere?

ADVOKAT: Pa, recimo, ako bi on bio odista naslednik?

DANICA (uvređeno): Zar vi odista niste mogli steći bolje mišljenje o meni?

ADVOKAT: Bože moj, neka vas to ne vređa, ali, znate kako je, bogatstvo ipak mora pokolebati čoveka.

DANICA: Tako? Znači, i vi se ne osećate jaki pred bogatstvom? (Nušić 2005: 301-302).
} 
La opinión de los familiares sobre Paula se evidencia en las siguientes líneas: «[...] ¿Qué tenía que hacer en una ceremonia íntima, alguien completamente ajeno a la familia?, se cuestionaban ofendidos los integrantes del clan» (Riquelme 2000: 57).

Danica también es vinculada al mencionado sentimiento de intrusión desde el primer momento en el que aparece, esto es, en la segunda escena del primer acto. En primer lugar, esto se observa en la acotación que acompaña la aparición de Danica: «[...] cuando aparece todos se callan, solo intercambian miradas y hacen indicaciones los unos a los otros de que no hay que hablar delante de ella [...]». Además existen varias intervenciones de los familiares que aluden a Danica con el mismo tono, una de ellas, por ejemplo, la siguiente intervención de Vida: «[...] Tenemos que saber, porque, la verdad, es vergonzoso lo que estamos viviendo: Aquí muchos somos parientes y familia, como se dice, y los forasteros nos reciben y nos sirven ${ }^{14}$.

La octava relación observada reside en el momento en que, después de la apertura del testamento, clave en ambas obras, se conocen las herederas principales, de las fortunas de don Agustín y de Mata Todorović, o sea, Paula y Danica. Obviamente, nadie de la familia, ni siquiera las herederas mismas, conocían el contenido del testamento, y por lo tanto, en las dos obras existe un factor de sorpresa una vez este es revelado.

Dicho momento se plasma en $H S$ en el siguiente fragmento, que comienza con el abogado sacando el testamento de su portafolio (Riquelme 2000: 59):

Una hoja solitaria y casi desnuda asomó a la vista de los presentes. La exclamación fue unánime: «¿Sólo cuatro líneas para repartir tan inmensa fortuna?». El abogado hizo caso omiso y empezó la lectura: Queridos hijos: De inmediato, tendrán que echar a la suerte sus ambiciones. Yo no les voy a robar mucho tiempo. Solamente el preciso para comunicarles que declaro a mi esposa única heredera. Me he casado con Paula.

El final del relato $H S$ abarca en estas palabras dos elementos clave, esto es, el instante culminante de la apertura del testamento y el conocimiento inesperado de que Paula es la única heredera y esposa del difunto don Agustín.

\footnotetext{
${ }^{14}$ Texto original en serbio: „[...] pri njenoj pojavi svi zaćute, razmenjuju samo poglede i daju jedno drugom znak da se pred njom ne govori [...] VIDA: [...] Treba da znamo, jer ovo je odista sramota što doživesmo: kraj toliko nas, koji smo rod i familija, što kažu, pa tuđin da nas dočekuje i da nas služi“ (Nušić 2005: 292-293).
} 
A diferencia del relato $H S$, en la obra teatral $F A$, el acto de abrir el testamento como tal no se escenifica, y, además, no cierra la obra. El momento culminante que cierra la obra $F A$ es cuando Agaton dice que «ha arreglado la cosa» haciendo referencia a su intento de engañar a todos haciéndoles creer que el abogado es su hijo extramatrimonial en un último intento de asegurase un pellizco de la fortuna del difunto, como hemos destacado al principio de este apartado.

En el siguiente diálogo se desvelan los detalles relacionados en $F A$ con la apertura del testamento, el conocimiento de la heredera y la sorpresa ligada al hecho de que Danica es hija extramatrimonial de Mata Todorović:

SIMKA: ¿Y a quién se lo dejó? ¿A quién?... A esa... no sé cómo decirlo.

GINA: ¡Dilo querida, dilo!

SIMKA: Pues que se lo dejara a una muchacha ilegítima.

TRIFUN: Bueno, también dejó algo a la Iglesia y a las escuelas.

SIMKA: Dejó algo, para guardar las apariencias y para tapar la vergüenza, pero todo lo demás es para ella: la casa, el viñedo, las tiendas, las acciones, el efectivo, todo, todo es para ella.

GUINA: ¡Todo, claro!

VIDA: ¿Y la ley permite eso compadre Proka, dejar la herencia a hijos ilegítimos?

PROKA: Mira, ahí el difunto nos ha engañado. Sin el conocimiento de la familia ha tenido una hija ilegítima.

SIMKA: Y no le dio vergüenza decir en público en el testamento que tiene una hija ilegítima.

GUINA: ¿Y veis ahora cómo fingía esa muchacha ante nosotros?

TANASIJE: A no, no hay que ser injustos ahí, ella no sabía nada. ¿Acaso no visteis que perdió el conocimiento...? ${ }^{15}$

${ }^{15}$ Texto original en serbio:

SIMKA: I kome ostavi? Kome?... Jednoj... ne znam kako da kažem?

GINA: Kaži, sestro, kaži!

SIMKA: Da ostavi jednoj vanbračnoj devojci.

TRIFUN: Pa ostavio je i crkvi i prosveti.

SIMKA: Ostavio je nešto, koliko reda radi i da pokrije sramotu, ali sve je ostalo njoj: kuću, vinograd, dućane, akcije, gotovinu, sve, sve njoj.

GINA: Sve bome!

VIDA: I zar može po zakonu, prijatelj-Proko, da se ostavlja vanbračnoj deci?

PROKA: E vidiš, i tu nam je pokojnik podvalio. Bez znanja familije on je imao vanbračnu ćerku.

SIMKA: I nije ga sramota bilo da javno u testamentu kaže da ima vanbračnu ćerku.

GINA: I vidite li vi samo kako se ta devojka pretvarala pred nama?

TANASIJE: A ne, tu ne treba grešiti dušu, ona nije ništa znala. Zar niste videli kako pade u nesvest...? (Nušić 2005: 343). 


\section{Conclusiones}

El análisis intertextual aplicado a las obras Herederos a la suerte de Yula Riquelme y La familia afligida de Bransilav Nušić nos ha permitido exponer las relaciones existentes entre dos obras literarias carentes de un vínculo referencial. A lo largo del análisis hemos podido ver ocho relaciones relevantes que se refieren al tema, al título, a los personajes, su carácter y actitudes, elementos estructurales de las obras y elementos temáticos relacionados con el fallecimiento y los correspondientes procedimientos legales y tradiciones. En ambas obras se realiza una crítica de la hipocresía y la avaricia y se observa cierta ironía en el título, ya que los herederos no son herederos a la suerte, y vemos que la familia no está afligida. Son claves los personajes femeninos de Paula y Danica que para la sorpresa de los supuestos herederos resultan ser las absolutas triunfadoras, no solo por el hecho de ser herederas, sino también por vencer ante la hipocresía y la avaricia de los herederos. Además, como hemos visto en los análisis literarios de las dos obras, la hipocresía y la avaricia de los herederos a su vez aluden a la hipocresía y la avaricia de la sociedad.

El marco teórico de la intertextualidad nos permite ver estas relaciones que acercan dos obras aparentemente lejanas, un relato corto de finales del siglo XX de una escritora paraguaya, y una obra de teatro del primer tercio del siglo XX de un escritor serbio. Consideramos que aquí precisamente reside el beneficio y el enriquecimiento que nos aporta una lectura intertextual tanto desde el punto de vista personal (de lector) como lingüístico, estético y cultural.

La intertextualidad puede ser útil, siempre y cuando la delimitemos y apliquemos a un análisis concreto, sin desatender el análisis y la crítica literarios. Aparte de su utilidad para determinados análisis de obras literarias y de otras formas de arte, también se ha señalado por parte de muchos investigadores y docentes el potencial de la intertextualidad para la enseñanza, consideración que compartimos.

La intertextualidad sigue vigente, ya que es una perspectiva que nos permite descubrir relaciones y puntos de encuentro entre diferentes obras de arte y contextos culturales donde quizá no eran de esperar, y en esta vertiente, en su potencial de descubrir y hacer visibles puntos de encuentro, consideramos que reside una de sus mayores virtudes. 


\section{REFERENCIAS BIBLIOGRÁFICAS}

Barthes 1994: Roland Barthes. El susurro del lenguaje. Más allá de la palabra y de la escritura. Barcelona: Paidós.

Đoković 1964: Милан Ђоковић. Бранислав Нушић. Београд: Нолит.

Gligorić 1964: Велибор Глигорић. Бранислав Нушић. Београд: Просвета.

Instituto Cervantes. Diccionario de términos clave de ELE. Centro Virtual Cervantes. Web. 05/11/2019.

Kristeva 1981: Julia Kristeva. Semiótica 1. Madrid: Fundamentos.

Lešić 2011: Andrea Lešić. Bahtin, Bart, stukturalizam: književnost kao spoznaja i mogućnost slobode. Beograd: Službeni glasnik.

Nušić 2005: Бранислав Нушић. Сабрана дела Бранислава Ђ. Нушића (књига друга). Београд: Просвета.

Nušić 2013: Branislav Nušić. El sospechoso. Belgrado: Fokus. Forum za interkulturnu komunikaciju. Web. 30/09/2019.

Peiró \& Rodríguez Alcalá 2000: José Vicente Peiró \& Guido Rodríguez Alcalá. Narradoras paraguayas (antología). Alicante: Biblioteca Virtual Miguel de Cervantes. Web. 10/09/2019.

Peiró Barco 2002: José Vicente Peiró Barco. Literatura y sociedad. La narrativa paraguaya actual (1980-1995). Alicante: Biblioteca Virtual Miguel de Cervantes. Web. 10/09/2019.

Presa González 1997: Fernando Presa González (ed.), Historia de las literaturas eslavas. Madrid: Cátedra.

Riquelme de Molinas 2000: Yula Riquelme de Molinas. Bazar de cuentos. Alicante: Biblioteca Virtual Miguel de Cervantes. Web. 01/09/2019. Soldatić 2010: Dalibor Soldatić. «Las literaturas hispánicas en Serbia». Colindancias, 1: 21-28. Web. 20/09/2019.

Thörnryd 2008: Victoria Thörnryd. «Lo fantástico feminista en cuatro cuentos de Yula Riquelme». ANALES Nueva Época, 11: 227-242. Web. 10/09/2019. 


\section{INTERTEXTUAL ANALYSIS AS A MEETING POINT: BRANISLAV NUŠIĆ Y YULA RIQUELME}

\section{Summary}

The concept of intertextuality has had a great echo in the literary analysis since its' inception in the second half of the 20th century. We consider that this concept can offer a valid theoretical framework if it is specified and if it does not pretend to substitute the literary analysis or literary criticism. It is useful especially bearing in mind its' potential of showing relations amongst apparently unrelated literary works.

We present in this paper an intertextual analysis of two literary works. A short story by a Paraguayan writer Yula Riquelme, published in the 1990s and a theatrical comedy by the Serbian writer Branislav Nušić, written in the 1830s. As there is no evidence of any existence of referentiality between these two works, intertextuality becomes the most appropriate theoretical framework in order to outline the relations that we have found between them two.

The main subject in both works is the demise and the subsequent situation afterwards which involves the heirs and the opening of the will. We will see the different relations that exist between these two works concerning various elements such as the subject, the title, the individual characters, their personalities and attitudes also structural elements of the literary works and other elements that are concerned with the demise and the corresponding legal procedures and traditions. Our analysis will allow us to see relations between two literary works that are distant from a geographical, linguistic, cultural and temporal point of view, but close, if we look at them from the perspective of intertextuality. Nušić.

Keywords: intertextuality, textual relations, Yula Riquelme, Branislav 